\title{
Syntheses of Coumarins in Environmentally Friendly Ionics Liquids
}

\author{
Sanita Pavlovica ${ }^{*}$ and Andris Zicmanis \\ University of Latvia, Riga LV-1586, Latvia
}

Received: December 31, 2013 / Accepted: January 14, 2014 / Published: March 25, 2014.

\begin{abstract}
Syntheses of 3-substituted coumarins by the condensation reaction of salicylaldehyde with activated methylene compounds (ethyl cyanoacetate, malonic acid) are discussed in media of ionic liquids-(2-hydroxyethyl)ammonium carboxylates (formates, acetates, lactates) without utilization of any other catalysts. The dependence of yields of the reaction product is investigated on the structure of ionic liquids (their cations, anions, total polarity and pseudo-pH values). 3-Substituted coumarins are prepared in high yields in media of these environmentally friendly ionic liquids which serve simultaneously as reaction media and as catalysts. The mentioned ionic liquids are prepared by reactions of corresponding hydroxyethyl-amines with carboxylic acids, and their quantitative analyses being made by potentiometric titration of ionic liquids with perchloric acid in $100 \%$ acetic acid.
\end{abstract}

Key words: Coumarin, condensation reaction, ionic liquid, potentiometric titration.

\section{Introduction}

Coumarins and their derivatives form an important group of heterocyclic compounds [1]. A large number of natural products contain coumarin cycle. Coumarins are successfully used for preparation of different materials - optical brighteners [2, 3], chromophoric compounds [4-6], etc.. They are also widely used in biological and medicinal research, and especially coumarin-3-carboxylic acid and other 3-substituted coumarins. These compounds have shown anticancer activity [7, 8], antimicrobial activity [9], lipid lowering effect [10], a possibility to inhibite acetylcholinesterase [11], monoamine oxidase [12] and other enzymes.

Several good methods exist for syntheses of 3-substituted coumarins, the Knoevenagel condensation of salycilaldehyde with activated methylene compounds being the most popular. The reaction needs the assistance of a catalyst - ammonium or substituted ammonium acetate [13], hydrotalcite [14] etc.. First

\footnotetext{
*Corresponding author: Sanita Pavlovica, Ph. Student, research fields: organic chemistry, ionic liquids, homogeneous synthesis and heterocyclic synthesis. E-mail: sanita.pavlovica@gmail.com.
}

attempts are made to prepare of 3-substituted coumarins in media of ionic liquids [15-17], and this possibility looks rather promising in future [17].

Coumarin synthesis requires rather harsh reaction conditions and the utilization of volatile and unhealthy organic solvents, and their replacement by ionic liquids presents a very promising alternative solution of the problem. Nowadays, ionic liquids have attracted extensive interest as environmentally benign solvents due to their favorable properties including syntheses of heterocyclic compounds [18]. Unfortunately, the used ionic liquids are not environmentally quite friendly materials. Therefore, another possibility is considered in the following communication - the possibility to obtain 3-substituted coumarins in media of recently proposed highly biodegradable and essentially non-toxic ionic liquids-(2-hydroxyethyl)ammonium carboxylates [19-29].

\section{Experiments}

\subsection{Instruments, Reagents and Materials}

${ }^{1} \mathrm{H}$ NMR (proton nuclear magnetic resonance) spectra were recorded on a Varian 400 MR 
spectrometer, using DMSO- $\mathrm{d}_{6}$ (dimethyl sulfoxide) as a solvent and TMS (tetramethylsilane) as an internal standard. FT-IR (Fourier transform infrared) spectrometer Avatar 330 FT-IR Thermo Nicolet; The polarity of ILs was evaluated (and $E_{T}^{N}$ calculated) according to a described method [24] using Reichardt's dye and a Perkin-Elmer Lambda 25 UV/Vis (Ultraviolet-visible) spectrophotometer. Data were processed with the program Lambda 25 UV Win Lab. HPLC/MS (high performance liquid chromatography/mass spectrometry) analyzes were performed on the liquid chromatograph Waters Alliance 2690, using detector Micromass ${ }^{\circledR}$ Quattro MicroTM API (atmospheric pressure ionization) with $\mathrm{ES}^{+} / \mathrm{MS}$ (electrospray ionization positive mode). Water content was determined with Karl Fischer titrator Metrohm 836 Titrant, cylinder volume $20 \mathrm{~mL}$. $\mathrm{pH}$ of water solutions of ILs $(0.1 \mathrm{~mol} / \mathrm{L})$ was measured by a pH meter AD (Adrona) 1405. Quantitative analyses of ILs were made with automatic potentiometric titrator 785 DMP (dimethyl phthalate) Titrino (Metrohm) with a burette $(20 \mathrm{~mL})$ and Solvotrode for non-aqueous titration (Metrohm AG 9101 Herisau).

Salycilaldehyde and ethyl cyanoacetate (Aldrich) were distilled in vacuum before use, malonic acid (Aldrich) was used as received. Ionic liquids were obtained in reactions of (2-hydroxyethyl)amines with corresponding carboxylic acids, as described elsewhere [19-29]. Their structures were confirmed by ${ }^{1} \mathrm{H}$ NMR spectroscopy and HPLC/MS. Some characteristics of these materials useful for their utilization in organic syntheses are presented in Table 1. Perchloric acid standard solution, $0.05 \mathrm{~N}$ in glacial acetic acid (Aldrich), and acetic acid, 99.8\% (Acros) were used as received for quantitative analyses of ILs.

2.2 Quantitative Analyses of Ionic Liquids-Potentiometric Titration in Non-aqueous Medium

Potentiometric titration of ILs-(2-hydroxyethyl) ammonium carboxylates (1-3) (general procedure). A sample of an ionic liquid (100-120 mg) was dissolved in glacial acetic acid $(50 \mathrm{~mL})$ and titrated with the solution of perchloric acid in glacial acetic acid $(0.05$ $\mathrm{mol} / \mathrm{L}$ ). The purity (content of the main substance, \%) of the sample was calculated, and results are presented in Table 1.

\subsection{Syntheses of Coumarin Derivatives}

\subsubsection{Coumarin-3-Carboxylic Acid (6)}

Salycilaldehyde ( $0.61 \mathrm{~g}, 5.00 \mathrm{mmol})$, malonic acid $(0.62 \mathrm{~g}, 6.00 \mathrm{mmol})$ and 2-hydroxyethylammonium acetate $(1.21 \mathrm{~g}, 10.00 \mathrm{mmol})$ were stirred at $90{ }^{\circ} \mathrm{C}$ for $1 \mathrm{~h}$. The mixture was cooled to $\sim 70{ }^{\circ} \mathrm{C}$, ethanol $(10$ $\mathrm{mL}$ ) was added and the mixture was stirred for $15 \mathrm{~min}$. The precipitate formed was separated, washed with water $(2 \times 5 \mathrm{~mL})$ on the filter, and dried in open air. The technical product was crystallized from the mixture hexane-ethyl acetate (2:3). Coumarine-3-carboxylic acid (6, 0.86 g, 91\%) was obtained as a white crystalline substance with m.p. 190-191 ${ }^{\circ} \mathrm{C}$ (lit. [13] m.p. 191-192 ${ }^{\circ} \mathrm{C}$ ). IS spectrum (nujol, $v, \mathrm{~cm}^{-1}$ ): 3,223 (m, O-H), 2,926 (s, C-H), 1,743 (s, C=O), 1,624 (m, C=C), 1,282 (m, C-O). ${ }^{1} \mathrm{H}$ NMR spectrums $\left(\mathrm{DMSO}^{-} \mathrm{d}_{6}, \delta, \mathrm{ppm}\right): 7.20(\mathrm{~d}, 1 \mathrm{H}, \mathrm{Ar}-\underline{\mathrm{H}})$; 7.23-7.32 (m, 3H, Ar- $\underline{\mathrm{H}}) ; 7.48$ (d, 1H, Ar- $\underline{\mathrm{H}})$; 7.49-7.56 (d, 1H, Ar- $\underline{\mathrm{H}}) ; 7.69$ (d, 1H, Ar- $\underline{\mathrm{H}}) ; 9.11$ (s, 1H, O- $\underline{H})$. EIMS, m/z, \%: $190\left(15, \mathrm{M}^{+}\right), 146$ (50), 118 (100), 90 (50), 63 (40), 44 (40).

Coumarine-3-carboxylic acid (6) was prepared in a similar way also in other ionic liquids (1-3), and results are presented in Figs. 1-4.

2.3.2 2-Imino-2H-1-Benzopyran-3-Carboxylic Acid Ethyl Ester (8)

Salycilaldehyde $(0.61 \mathrm{~g}, \quad 5.00 \mathrm{mmol})$, ethyl cyanoacetate $(1.13 \mathrm{~g}, \quad 10.00 \mathrm{mmol})$ and 2-hydroxyethylammonium acetate $(1.21 \mathrm{~g}, \quad 10.00$ $\mathrm{mmol}$ ) were stirred at room temperature for $30 \mathrm{~min}$. The reaction mixture becomes solid and yellow. Water $(15 \mathrm{~mL})$ was added to it, and the mixture was stirred further for $15 \mathrm{~min}$. The obtained precipitate was 
separated, washed with water $(2 \times 5 \mathrm{~mL})$ on the filter, and dried in open air. The technical product was crystallized from ethanol. 2-Imino-2H-1-benzopyran-3-carboxylic acid ethyl ester $(8,1.07 \mathrm{~g}, 99 \%)$ was obtained in form of light yellow crystals with m.p. $135{ }^{\circ} \mathrm{C}$ (lit. [30] m.p. 135-136 $\left.{ }^{\circ} \mathrm{C}\right) .{ }^{1} \mathrm{H}$ NMR spectrum $\left(\mathrm{CDCl}_{3}, \delta, \mathrm{ppm}\right)$ : 8.53 (s, 1H, N-프); 7.64-7.61 (m, 2H, Ar- $\underline{\mathrm{H}}$ ); 7.36-7.30 (m, 2H, Ar- $\underline{\mathrm{H}}) ; 4.41$ (q, 2H, -O- $\left.\mathrm{CH}_{2}-\mathrm{CH}_{3}\right) ; 3.48$ (s, 1H, $-\mathrm{C}=\mathrm{C} \underline{\mathrm{H}}-) ; 1.41\left(\mathrm{t}, 3 \mathrm{H},-\mathrm{O}-\mathrm{CH}_{2}-\mathrm{C}_{3}\right) . \mathrm{EIMS}, \mathrm{m} / \mathrm{z}, \%$ : 218 (15, M + 1), 190 (100), 172 (98), 128 (8).

2-Imino-2H-1-benzopyran-3-carboxylic acid ethyl ester (8) was prepared in a similar way also in other ionic liquids (1-3) and results are presented in Figs. $5-8$.

\section{Results and Discussion}

Nowadays ionic liquids (ILs) are widely used as solvents for various organic transformations in place of common organic solvents. It is possible to form purposely the best structure of these solvents for the selected reaction. The main disadvantages of imidazolium and pyridinium-based ILs are their high toxicity and low biodegradability. In its turn, (2-hydroxyethyl) ammonium carboxylates (1-3) that were recently developed in several laboratories, including our, successfully solve the problem - they are highly biodegradable and essentially non-toxic [28, 29]. Apart from it, these ILs can be easily prepared in high yields by simple neutralization reactions of (2-hydoxyethyl) amines by corresponding carboxylic acids. For the confirmation of their structures and qualitative analyses, ${ }^{1} \mathrm{H}$ NMR spectroscopy and mass spectrometry was applied.

Quantitative analysis of ILs is not sufficiently developed at present. HPLC/MS and rarely ion chromatography are the most frequently used methods of evaluations of the quality of ILs. Unfortunately, the accuracy of these methods allows expecting better. Potentiometric titration is by far more accurate method of quantitative analysis. Therefore, the mentioned titration of ILs in non-aqueous solution-acetic acid (100\%) is developed in our laboratory recently (Scheme 1). (2-hydroxyethyl) ammonium carboxylates were titrated with $\mathrm{HClO}_{4}$ $(0.05 \mathrm{~mol} / \mathrm{L})$ in solutions of samples in pure acetic acid (100\%), the automatic titrator serving well for reaching high accuracy. Titration curves are of high quality, and there is no problem of reading the point of equivalence. Results obtained in such a way have confirmed that ILs (1-3) prepared as mentioned above contain the pure substance $\geq 98 \%$, and these measurements are very much more accurate than those obtained by HPLC/MS. The missing $\leq 2 \%$ forms water that appears in ILs even after careful drying in vacuum, because of high hygroscopicity of these hydrophilic materials. Independent measurements of the water content in ILs (Karl Fischer method) have confirmed the mentioned hypothesis. The most significant characteristics necessary for exploitation of chosen ILs in organic syntheses are collected in Table 1.

The authors' previous experiments have acknowledged that condensation reactions of benzaldehyde with activated methylene compounds proceed very efficiently in media of (2-hydroxyethyl)-ammonium carboxylates [28, 29]. Therefore, the applicability of these ILs was tested also for syntheses of coumarins in this communication.

The reaction of salicylaldehyde (4) with malonic acid (5) was performed in the media of (2-hydroxyethyl) ammonium carboxylates during $1 \mathrm{~h}$ at $90{ }^{\circ} \mathrm{C}$ (Scheme 2). The resulting coumarin-3-carboxylic acid (6) was separated from the reaction mixture by dissolving ionic liquid in ethanol. Yields of the isolated and crystallized product (6) have reached $91 \%$ in the very best reaction conditions.

It should be noticed that the highest yields of the coumarin-3-carboxylic acid (6) were reached in those ILs that have contained only one hydroxyethyl group $(1 \mathrm{a}, 1 \mathrm{~b}, 1 \mathrm{c})$. Yields of the product (6) in bis- and tris-(2-hydroxyethyl) ammonium carboxylates (2a, 2b, 


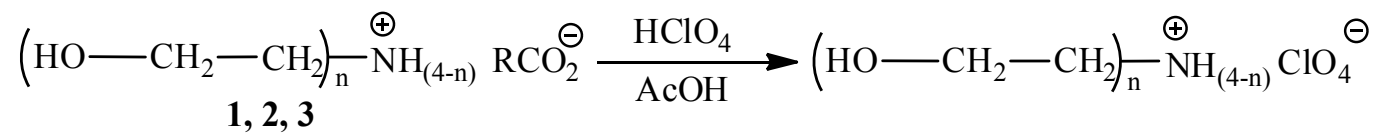

where: 1) $n=1$; 2) $n=2$; 3) $n=3$

a) $\mathrm{R}=\mathrm{H}$; b) $\mathrm{R}=\mathrm{CH}_{3}$; c) $\mathrm{R}=\mathrm{CH}_{3} \mathrm{CH}(\mathrm{OH})$

Scheme 1 (2-hydroxyethyl) ammonium carboxylates and their quantitative analysis.

Table 1 Exploitation characteristics of used ILs-(2-hydroxyethyl) ammonium carboxylates (1-3).

\begin{tabular}{|c|c|c|c|c|c|c|}
\hline $\mathrm{IL}$ & Number of OH groups in IL (n) & M.p. $\left({ }^{\circ} \mathrm{C}\right)$ & Assay $(\%)^{\mathrm{a}}$ & Moisture (\%) ${ }^{\mathrm{b}}$ & $E_{T}^{N^{c}}$ & pseudo-pH ${ }^{\mathrm{d}}$ \\
\hline $1 \mathrm{a}$ & 1 & liquid & 98.6 & 2.2 & 0.94 & 6.3 \\
\hline $1 b$ & 1 & $60-61$ & 99.0 & 1.3 & 0.88 & 6.9 \\
\hline $1 \mathrm{c}$ & 1 & liquid & 98.7 & 1.8 & 0.89 & 6.7 \\
\hline $2 \mathrm{a}$ & 2 & liquid & 98.5 & 2.5 & 1.00 & 6.3 \\
\hline $2 b$ & 2 & liquid & 98.8 & 1.1 & & 6.7 \\
\hline $2 \mathrm{c}$ & 2 & liquid & 98.3 & 2.3 & 0.93 & 6.4 \\
\hline $3 a$ & 3 & $67-68$ & 98.9 & 0.6 & & 5.7 \\
\hline $3 b$ & 3 & $50-51$ & 99.1 & 0.4 & 0.97 & 6.1 \\
\hline $3 c$ & 3 & $45-46$ & 98.8 & 0.4 & 1.00 & 5.7 \\
\hline
\end{tabular}

${ }^{\mathrm{a}}$ Measured by potentiometric titration with perchloric acid in acetic acid (100\%);

${ }^{\mathrm{b}}$ Determined by the Karl Fischer method;

${ }^{c}$ Measured according to the described Reichardt's procedure [31];

${ }^{\mathrm{d}}$ Measured for concentrations of ILs in water $(0.10 \mathrm{~mol} / \mathrm{L})$.<smiles></smiles>

Scheme 2 Syntheses of coumarin derivatives in ionic liquid media.

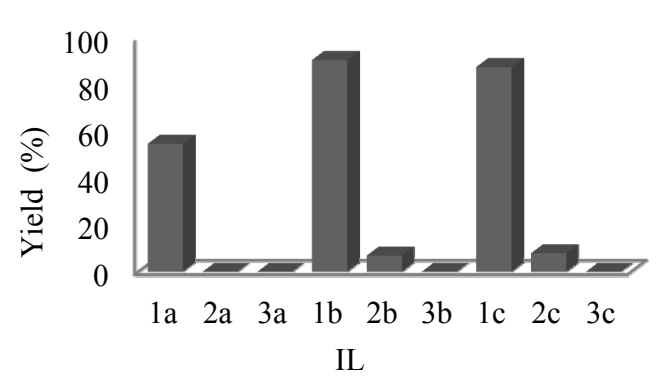

Fig. 1 Yields (\%) of coumarin-3-carboxylic acid (6) in ILs media.

2c, 3a, 3b, 3c) were negligible (Fig. 1).

Nine earlier described different highly hydrophilic ionic liquids (1-3) have been systematically tested as media for the synthesis of coumarins. They have had various numbers of hydroxyl groups (1-3) and different anions (formate, lactate, acetate). Anions have been selected purposely in order to obtain increasing their basicity starting from less basic formate anion and going to the more basic acetate anion.

Yields of coumarin-3-carboxylic acid (6) in the investigated condensation reaction have turned out to be heavily dependent on the structure of IL used (1-3) (Fig. 2). A close comparison of these structures reveals highly superior impact of the ILs that are based on 2-aminoethanol (1) by comparison with more substituted other (2-hydroxyethyl)ammonium carboxylate $(2,3)$. It allows assuming that primary aminogroup of ILs (1) possibly interacts with aromatic aldehyde group and so activates it. 


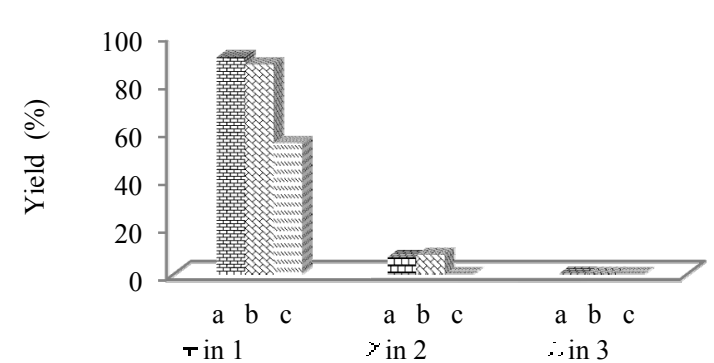

Fig. 2 The impact of the structure of the cation and anion in ILs on the yield (\%) of coumarin-3-carboxylic acid (6).

In order to explain contradicting results, the total polarity of used ionic liquids (expressed by the Reichardt's constant $E_{T}^{N}$ ) and yields of coumarin-3-carboxylic acid (6) were compared (Fig. 3). A rather narrow window of the total polarity turns out to be beneficial for the synthesis of the expected product. It corresponds approximately to the polarity of 0.88-0.90 in the Reichardt's scale and is more polar than the polarity of ethanol (0.65) and methanol (0.76) - traditional solvents for these reactions. The reaction in the medium of 1-heptylpyridinium bromide (10) that has Reichardt's constant $E_{T}^{N}-0.84$ and was investigated just for comparison also has practically no yield of the reaction product (6).

The reaction of salycilaldehyde (4) with malonic acid (5) traditionally proceeds in an organic solvent and compulsory is catalyzed by a base or an acid. At present, no method is available for determination of the true acidity/basicity of ILs. The nearest approximation might be the acidity of their water solutions-their pseudo-pH values. Such an assumption seems to be valid because the total polarity of used ILs is quite close to that of water. Comparison of the yields of coumarin-3-carboxylic acid (6) and measured pseudo-pH data of ILs shows that again only a narrow pseudo-pH value region (6.68-7.15) is advantageous for the formation of coumarin-3-carboxylic acid with acceptable yields (Fig. 4). The reaction in the medium of 1-ethyl-3-methylimidazolium ethyl sulfate (9) that has pH 7.2 in water solution and was investigated just for comparison also has practically no yield of the

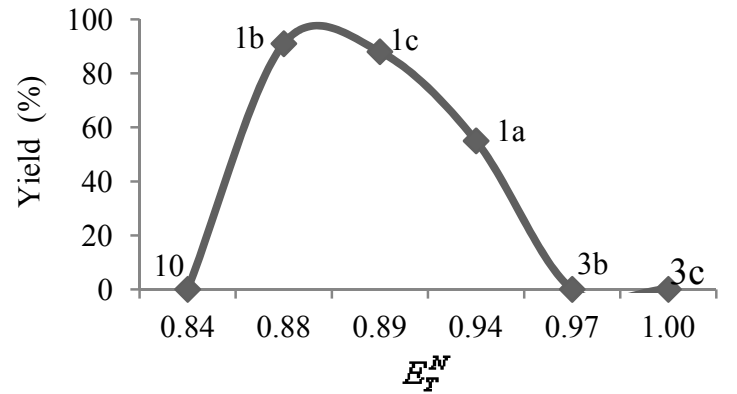

Fig. 3 The impact of the total polarity of a ILs on the yield (\%) of coumarin-3-carboxylic acid (6).

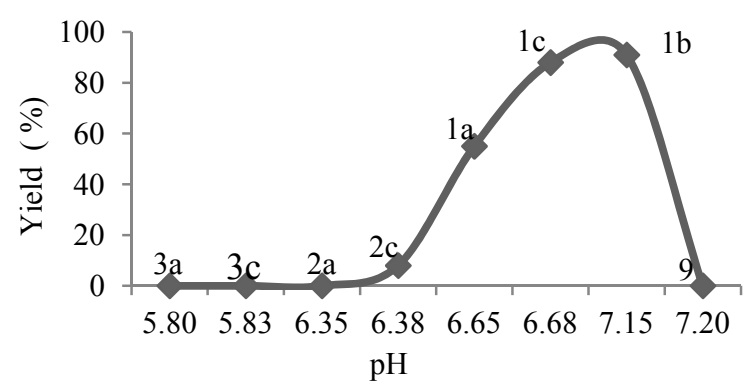

Fig. 4 The impact of the pseudo-pH value of a ILs on the yield (\%) of coumarin-3-carboxylic acid (6).

reaction product (6).

The reaction of salycilaldehyde (4) with ethyl cyanoacetate (7) proceeds very much easier by comparison with the previous one. This reaction was carried out in the media of the earlier described environmentally friendly ILs. The reaction does not need heating but proceed at room temperature (Scheme 2). The condensation reaction product (8) was separated from the reaction mixture by dissolving ionic liquid in water. After drying, the product was purified by crystallization or chromatography (silica gel; petroleum ether-EtOAc, 3:2). The reaction leads to the formation of 3-substituted coumarin derivative-2-imino-2H-1-benzopyran-3-carboxylic acid ethyl ester (8), the yield reaching 96\% (Fig. 5). It should be emphasized that no extra catalyst was needed in these condensation reactions, ILs themselves serving both as catalysts and as reaction media.

Structures of the examined (2-hydroxyethyl) ammonium carboxylates demonstrate equally close impact on the yields of the condensation reaction product-2-imino-2H-1-benzopyran-3-carboxylic acid 


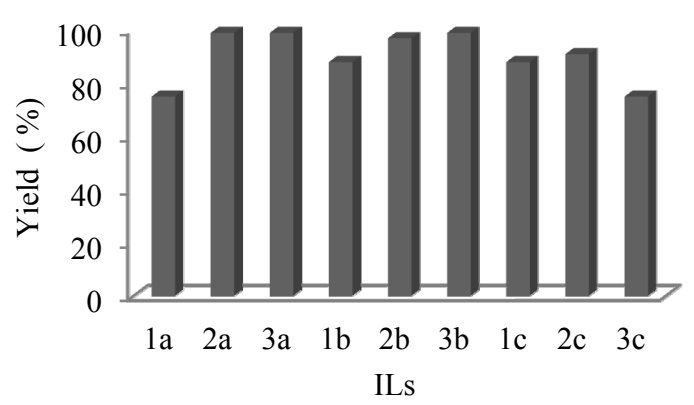

Fig. 5 Yields (\%) of 2-imino-2H-1-benzopyran -3-carboxylic acid ethyl ester (8) in ILs media.

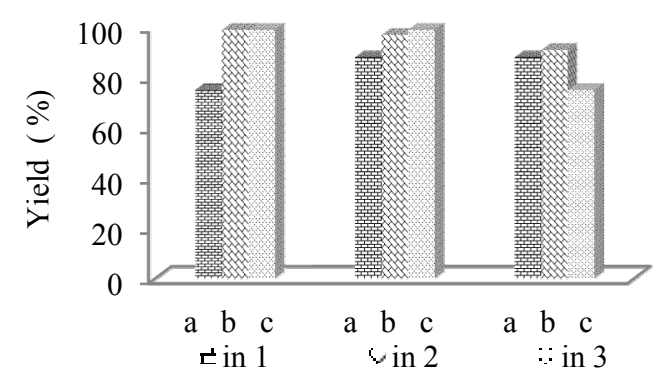

Fig. 6 The impact of the structure of the cation and anion in ILs on the yield (\%) of 2-imino-2H-1-benzopyran -3-carboxylic acid ethyl ester (8).

ethyl ester (8), (Figs. 5 and 6). Yields of the reaction are high, and only the yield in the medium of triethanolammonium lactate $(3 \mathrm{c})$ is somehow lower, most likely, because of interferences of large cation and anion.

Further the influence of the pseudo-pH and total polarity of ILs (1-3) on yields of the coumarin derivative (8) was examined more closely. High yields were obtained in relatively narrow and only slightly acidic pseudo-pH interval: 5.8-6.7 (Fig. 7). This fact suggests that neutral or basic media are not at all favorable for the coumarin synthesis. The fact is also confirmed by an experiment that the yield of the same coumarin (8) in ethanol in the presence of piperidine is quite moderate $(30 \%-40 \%$, measured by $\mathrm{GC} / \mathrm{MS}$ in our laboratory).

The impact of total polarity on the yield of the product (8) is shown in Fig. 8. Experiments clearly certify that highly polar ILs are more pertinent for syntheses of coumarins (8) than medium or non-polar media. The highest yields of coumarins (8) are

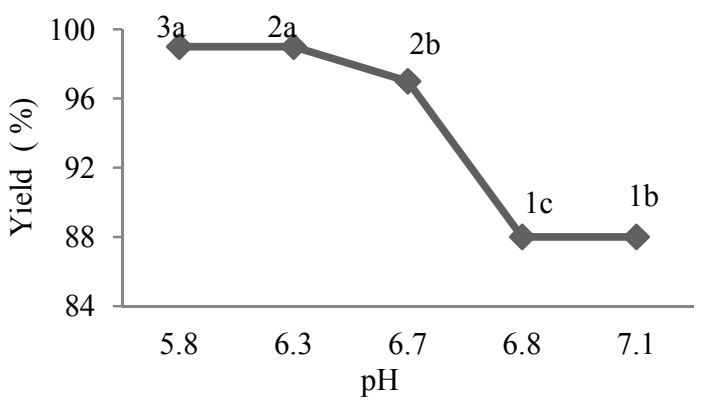

Fig. 7 The impact of the pseudo-pH value of a ILs on the yield (\%) of 2-imino-2H-1-benzopyran-3-carboxylic acid ethyl ester (8).

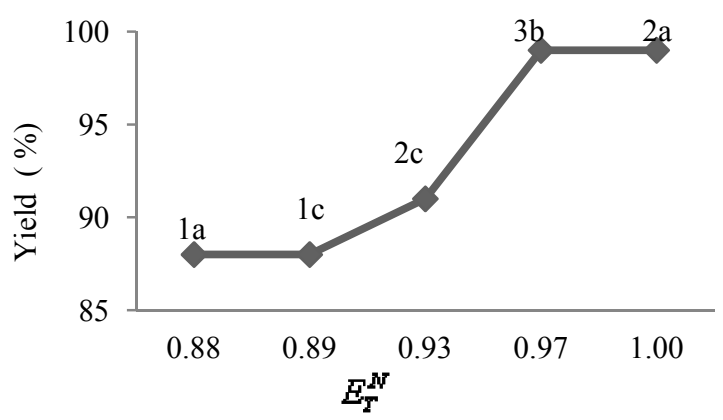

Fig. 8 The impact of the total polarity of a ILs on the yield (\%) of 2-imino-2H-1-benzopyran-3-carboxylic acid ethyl ester (8).

obtained in ILs with the Reichardt constant $E_{T}^{N}=$ 0.93-1.00. Again it should be noted that these ionic liquids serve both as reaction media and as catalysts. No other catalysts are needed in these reactions because very high yields of the product $(\geq 99.0 \%)$ can be reached even at room temperature.

\section{Conclusions}

Syntheses of coumarins in media of ionic liquids are friendlier towards environment and simpler than reactions in organic solvents. They facilitate the separation of the product and do not need the presence of any other catalyst. Yields of the products-coumarin-3-carboxylic acid and 2-imino-2H-1-benzopyran-3-carboxylic acid ethyl ester depend on the structure of used ionic liquid: the total polarity and the acidity of the reaction medium created by the exploited ionic liquid. The ionic liquids useful for these cyclization reactions can be easily prepared by reactions of (2-hydroxyethyl) amines with corresponding carboxylic acids. These ionic liquids 
can be successfully analyzed by potentiometric titration with perchloric acid in solutions of acetic acid.

\section{Acknowledgments}

Authors are grateful to the European Social Fund for financial support of the research and Mr. E. Pridans and Dr. U. Kalejs from the BAPEKS, Ltd. (Latvia) for help with the potentiometric titration.

\section{References}

[1] Kennedy, R. O.; Thornes, R. D. Coumarins: Biology, Applications and Mode of Action; John Wiley and Sons: Chichester, 1997.

[2] Zabradnik, M. The Production and Application of Fluorescent Brightening Agents; John Wiley and Sons: New York, 1992.

[3] Heravi, M. M.; Sadjadi, S.; Oskooie, H. A .; Shoar, R. H.; Bamoharram, F. F. Catal. Commun. 2008, 9, 470-474.

[4] Fortier, J. E.; Even-Hernandez, P.; Baros, R.; Poulain, S.; Martinet, N.; Donner, M.; et al. Dyes and Pigments 2009, 80, 115-120.

[5] Peng, M. S.; Cai, J. Dyes and Pigments 2008, 79, 270-272.

[6] Maeda, M. Laser Dyes; New York, 1994.

[7] Paul, K.; Bindal, S.; Luxami, V. Bioorganic \& Medicinal Chemistry Letters 2013, 23, 3667-3672.

[8] Kempen, I.; Hemmer, M.; Counerotte, S.; Pochet, L.; Tullio, P.; Foidart, J. M.; et al. European J. Med. Chem. 2008, 43, 2735-2750.

[9] Creaven, B. S.; Egan, D. A.; Kavanagh, K.; Mccann, M.; Noble, A.; Thati, B.; et al. Inorganica Chimica Acta 2006, 359, 3976-3984.

[10] Sashidhara, K. V.; Palnati, G. R.; Sonkar, R.; Avula, S. R.; Awasthi, C.; Bhatia, G. European J. Med. Chem. 2013, 64, 422-431.

[11] Catto, M.; Pisani, L.; Leonetti, F.; Nicolotti, O.; Pesce, P.; Stefanachi, A.; et al. Bioorganic \& Medicinal Chemistry 2013, 21, 146-152.

[12] Secci, D.; Carradori, S.; Bolasco, A.; Chimenti, P.; Yáñez,
M.; Ortuso, F.; et al. European J. Med. Chem. 2011, 46, 4846-4852.

[13] Song, A.; Wang, X.; Lam, K. S. Tetrahedron Letters 2003, 44, 1755-1758.

[14] Angelescu, A.; Pavel, O. D.; Birjega, R.; Zăvoianu, R.; Costentin, G.; Che, M. Applied Catalysis A: General 2006, 308, 13-18.

[15] Potdar, M. T.; Rasalkar, M. S.; Mohile, S. S.; Salunkhe, M. K. J. Mol. Catalysis A: Chemical 2005, 235, 249-252.

[16] Singh, V.; Kaur, S.; Sapehiyia, V.; Singh, J.; Kad, G. L. Catal. Commun. 2005, 6, 57-60.

[17] Phadtare, S. B.; Jarag, K. J.; Shankarling, G. S. Dyes and Pigments 2013, 97, 105-112.

[18] Martins, M. A. P.; Frizzo, C. P.; Moreira, D. N.; Zanatta, N.; Bonacorso, H. G. Chem. Rev. 2008, 108, 2015-2050.

[19] Bicak, N. J. Mol. Liquids 2005, 116, 15-18.

[20] Zhai, L.; Zhong, Q.; He, C.; Wang, J. J. Hazard. Mater. 2010, 177, 807.

[21] Suzuki, H.; Yoshioka, S.; Igesaka, A.; Nishioka, H.; Takeuchi, Y. Tetrahedron 2013, 69, 6399-6403.

[22] Hossain, M. I.; El-Harbawi, M.; Noaman, Y. A.; Bustam, M. A. B.; Alitheen, N. B. M.; Affandi, N. A.; et al. Chemosphere 2011, 84, 101-104.

[23] Richter, K.; Bäcker, T.; Mudring, A. V. Chem. Commun. 2009, 301-303.

[24] Choi, H. M.; Kwon, I. Industrial\&Engineering Chemistry Research 2011, 50, 2452-2454.

[25] Suzuki, H.; Yoshioka, S.; Igesaka, A.; Nishioka, H.; Takeuchi, Y. Tetrahedron 2013, 6399-6403.

[26] Yuan, X.; Zhang, S.; Liu, J.; Lu, X. Fluid Phase Equilibria 2007, 257, 195-200.

[27] Kurnia, K. A.; Harris, F.; Wilfred, C. D.; Abdul, M. M. I.; Murugesan, T. J. Chem. Thermodyn. 2009, 41, 1069-1073.

[28] Zicmanis, A.; Pavlovica, S.; Gzibovska, E.; Mekss, P.; Klavins, M. Latvian J. Chem. 2010, 269-276.

[29] Zicmanis, A.; Pavlovica, S.; Gzibovska, E.; Mekss, P.; Klavins, M. Green and Sustainable Chemistry 2011, 1, 103-110.

[30] Su, C.; Chen, Z.; Zheng, Q. Synthesis 2003, 4, 555-559.

[31] Reichardt, C. Green Chem. 2005, 7, 339-351. 